\title{
LETRAMENTO LITERÁRIO: FORMAÇÃO DO LEITOR DE LITERATURA EM TEMPOS DE TRANSIÇÃO PARADIGMÁTICA ${ }^{1}$
}

\author{
Francisco Neto Pereira Pinto* \\ Universidade Federal do Tocantins/Araguaína
}

\begin{abstract}
Resumo: Este texto é um recorte de capítulo de nossa Dissertação de Mestrado e busca discutir, do ponto de vista teórico, as imagens de leitor de literatura promovidas por alguns trabalhos que se ocupam do conceito de letramento literário e estabelece como objetivo verificar se aí é considerado o leitor real - aquele de fato encontrável em sala de aula da escola básica -, ou o leitor ideal - idealizado pelos estudos teóricos que se ocupam desse tipo de leitor. A pesquisa insere-se no campo da pedagogia da literatura e considera a mentalidade emergente do paradigma da complexidade e da transdisciplinaridade. No entanto, para não perder de vista as especificidades do literário, trazemos à discussão autores dos campos da Estética, Poética e Teoria Literária. Os resultados mostram que boa parte dos trabalhos promove a imagem do leitor ideal e, por isso, os classificamos como letramento literário cartesiano; porém, uns poucos já se alinham com os estudos da complexidade e da transdisciplinaridade, o que nos levou a chamá-los de letramento literário complexo.
\end{abstract}

Palavras-chave: Leitor de literatura. Letramento literário. Complexidade.

\section{Considerações inicias}

Neste artigo, examinamos alguns trabalhos que discorrem sobre o conceito de letramento literário com o objetivo de melhor compreender as caracterizações de leitor pinceladas por alguns estudiosos que se debruçam sobre o ensino da literatura e formação do leitor literário. À medida que nos atemos à noção de letramento literário, procuramos evidenciar quais imagens de leitor vão sendo construídas nos trabalhos analisados e, mesmo que o conceito de letramento seja fluido, o que implica dificuldades em postular consenso sobre as habilidades e competências prontas e acabadas que deveriam caracterizar o leitor literariamente letrado, nosso esforço concentra-se em filtrar que visão prevalece: se de leitor

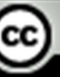

BY NC No Esta obra está licenciada sob uma Licença Creative Commons.

\footnotetext{
${ }^{1} \mathrm{O}$ texto é uma versão modificada de um capítulo de nossa Dissertação de Mestrado, defendida em inícios de 2013 no PPGL/UFT, campus de Araguaína, sob orientação da profa. Dra. Hilda Gomes Dutra Magalhães, a quem confiro o devido crédito.

* Mestre em Ensino de Língua e Literatura, pelo PPGL/UFT, e professor convidado na Universidade Federal do Tocantins, campus de Araguaína.
} 
ideal ou real.

Ao passo que esses são os objetivos delineados para esse capítulo, com o fim de atingi-los trazemos à discussão autores que inserem suas discussões no campo da pedagogia da literatura, da poética e da estética, o que é justificado pelo fato de que os pesquisadores que buscam pensar o letramento literário o fazem traçando as linhas diferenciais entre esse letramento e os demais por ancorarem seu pensamento nas especificidades do objeto literário segundo o que é tradicionalmente estabelecido sobre esse tipo de arte. Assim sendo, nesse capítulo dividimos nossa argumentação em dois momentos: no primeiro procuramos agrupar aqueles trabalhos que excluem a dimensão catártica da leitura literária como constitutiva do conceito de letramento e, no segundo, apresentamos trabalhos que alargam esse conceito de modo a abarcar essa e outras dimensões como caracterizadoras do leitor que faz uso efetivo da literatura.

Nesse mesmo sentido, relacionamos essas diferentes visões de letramento literário aos posicionamentos paradigmáticos neste trabalho chamados de cartesiano e complexo, posto eles encerrarem concepções, valores, atitudes, percepções e conformarem visões de realidade e orientarem práticas no mundo diferentemente, o que implica dizer, portanto, que o modo como os trabalhos voltados ao letramento literário veem a relação do leitor com esse tipo de texto, no percurso de formação escolar, está relacionado não somente às especificidades do literário em si, mas também ao ensino, à aprendizagem, à educação e ao próprio sujeito educando.

Ao falar de paradigma, não vamos restringir o significado do termo à esfera científica, tal como aparece em Thomas Kuhn (2009), pois nos parece bastante apropriado estender seu raio de abrangência a outros domínios, como o faz Fritjof Capra (2006), ao concebê-lo como uma constelação formada por concepções, valores, percepções e práticas que são compartilhados por uma comunidade e modela uma visão particular de realidade que, por sua vez, constitui-se como base da maneira pela qual a comunidade se organiza.

Compreender as questões paradigmáticas é da maior importância para os sistemas educacionais, visto que, como coloca Maria Cândida Moraes (1997), o modelo científico prevalecente em determinado momento histórico influencia nas teorias voltadas à aprendizagem que, por seu turno, reverberam efeitos na prática pedagógica. Assim, não é gratuita a prática do professor em sala de aula, quer dizer, sua maneira de trabalhar é testemunha de, entre outras, sua visão de educação, do posicionamento pedagógico adotado pela escola, do modelo educacional no qual se situa e, subjacente a tudo isso, encontra-se um 
paradigma científico com sua lógica de funcionamento que empresta sentidos a toda cadeia de relações.

Quanto ao paradigma da complexidade, compreendemos tratar-se de um conjunto de concepções, visões, princípios, valores e realizações que, sobretudo, ergue-se em reação ao paradigma ainda dominante, o cartesiano, que prima pela simplificação, separação e redução; contudo, não para negá-lo, mas para ir além, dando ênfase na relação e solidariedade entre as partes na constituição do todo. A complexidade, sob esse prisma, não perde de vista as singularidades associadas às partes, porém tem no horizonte o todo, que pode, às vezes, ser mais ou ser menos que a soma das partes, dada a natureza das interações entre elas ocorridas no processo relacional. A transdisciplinaridade, por seu turno, será assumida como um princípio do paradigma da complexidade (AKIKO SANTOS, 2009) e compreendida, a partir de Basarab Nicolescu (1999), como um visão diante do conhecimento e do mundo cujo “objetivo é a compreensão do mundo presente, para o qual um dos imperativos é a unidade do conhecimento" (NICOLESCU, 1999, p. 53 - grifo do autor).

Leitor de literatura ideal, aqui, é uma expressão tomada de empréstimo a Hans Jauss (2002a) para nos referir à figura do leitor de literatura que frequenta as páginas de trabalhos teóricos e orientações oficiais que versam sobre o que se espera que a escola forme como leitor literário. Constitui-se, ao cabo, em abstração e em uma finalidade em si. Para o autor, esse tipo de leitor é aquele que deve estar equipado não somente com "a soma de todo conhecimento histórico-literário atualmente disponível, mas também capaz de registrar conscientemente cada impressão estética e de ancorá-la numa estrutura de efeito do texto" (JAUSS, 2002a, p. 879).

Por seu turno, ao leitor de literatura real atribuímos o estatuto de qualquer indivíduo encontrável quer na escola ou em qualquer outro espaço lendo literatura que, por sua vez, tenha como suporte físico quer folhas de papel, como em livros, quer a tela de um aparelho eletrônico, como o computador. Trata-se, então, para usar as palavras de Paul Zumthor (2007, p. 23), de "um homem particular, feito de carne e de sangue" com seu peso, estatura e um conjunto de traços físicos, psíquicos e espirituais que o singulariza. Esse leitor é, quase sempre, nos trabalhos e orientações voltados à leitura literária o ponto de chegada, portanto, em nossa pesquisa, constitui-se em ponto de partida.

Do ponto de vista da complexidade, não há leitor ideal, mas sim indiviso em sua condição de humano, o que implica ser, de acordo com Edgar Morin (2007, p. 15), "a um só tempo físico, biológico, psíquico, cultural, social, histórico" etc. Assim, como leitor real 
estamos considerando a pessoa humana de carne, osso e espírito, dotada de razão, emoção e sexualidade, que é boa e má, que sonha, angustia-se, sofre e faz sofrer.... Por essa razão, nossa imagem de leitor real coloca-se como dinâmica e plástica, pois se ajusta a cada sujeito existente ou por vir, seja ele quem for.

\section{Sobre o letramento literário}

No que toca aos estudos voltados para o letramento, no Brasil, remontam à década de 1980 e avolumam-se os trabalhos que se inserem nessa área de estudos (SOARES, 2001; (KLEIMAN, 2001; TFOUNI, 2005, entre outros), o que não quer dizer, contudo, que o sentido para o termo letramento seja estável e inequívoco, pois, como diz Luiz Percival Britto (2004, p. 52), ele "pode ter várias significações, dependendo do tipo de raciocínio que se desenvolva" e, por isso, entendemos, com Magda Soares (2004), que letramento ainda é um termo com sentido fluido, dúbio e impreciso.

No entanto, trazemos aqui o entendimento de que, do ponto de vista individual, dizer que alguém é letrado hoje significa tomá-lo como capaz de "viver no mundo da escrita, dominar os discursos da escrita, ter condições de operar com os modos de pensar e produzir da cultura escrita (BRITTO, 2005, p. 13), ou seja, saber fazer uso efetivo e competente da tecnologia da escrita, o que envolve habilidades tais como:

\footnotetext{
capacidade de ler ou escrever para atingir diferentes objetivos - para informar ou informar-se, para interagir com outros, para imergir no imaginário, no estético, para ampliar conhecimentos, para seduzir ou induzir, para divertir-se, para orientar-se, para apoio à memória, para catarse...; habilidade de interpretar e produzir diferentes tipos e gêneros de texto; habilidade de orientar-se pelos protocolos de leitura que marcam o texto ou de lançar mão desses protocolos, ao escrever; atitudes de inserção efetiva no mundo da escrita, tendo interesse e prazer e ler e escrever, sabendo utilizar a escrita para encontrar ou fornecer informações e conhecimentos, escrevendo ou lendo de forma diferenciada, segundo as circunstâncias, os objetivos, o interlocutor (SOARES, 2004, p. 92).
}

Entretanto, é bom que digamos que os estudos envolvendo letramento hoje se desdobram em várias direções, como para os domínios da matemática e do mundo digital, por exemplo. No nosso caso interessa-nos compreender como esse conceito pode nos ajudar a olhar de perto a questão da formação do leitor literário, ou seja, o que se requer de um sujeito que lê literatura para que se diga dele como sendo um leitor que faz uso efetivo e competente da tecnologia da escrita literária de maneiras minimamente esperadas para sujeitos escolarizados.

É curioso notar que, de acordo com Britto (2004), há um senso comum, relativamente bem aceito na sociedade, de que entre as experiências com a leitura, à leitura 
literária é reservado um status bem particular, ou seja, ela é compreendida como a forma mais fundamental da experiência da leitura. Dito isso, surge a pergunta: o que se espera de um leitor literariamente letrado? O processo de letramento literário, que se realiza mediante usos de textos literários, engloba não apenas o uso social da escrita em uma dimensão diferenciada, “mas também, e sobretudo, uma forma de assegurar seu domínio" (COSSON, 2007, p. 12).

De acordo com o texto das Orientações Curriculares Nacionais (OCNs), "podemos pensar em letramento literário como estado ou condição de quem não apenas é capaz de ler poesia ou drama, mas dele se apropria efetivamente por meio da experiência estética, fruindoo" (BRASIL, 2006). Com base na definição acima, das OCNs (2006), a apropriação efetiva do texto literário por parte do leitor se dá por meio da experiência estética, que é a leitura do texto, segundo a perspectiva da fruição que, para o documento, é o mesmo que prazer estético. A essa visão de fruição poderíamos relacionar o conceito de aisthesis formulado por Jauss (2002b), que engloba o prazer derivado da percepção sensível e intelectual, cujos fundamentos remontam à Poética, de Aristóteles (2005), quando este fala do prazer que se pode derivar ante uma técnica perfeita de imitação como também em reconhecer uma imagem original no imitado.

Parece-nos que essa concepção de fruição, que embasa o conceito de letramento literário das OCNs (2006), exclui a dimensão passional na comunicação da literatura e seu leitor, que, ao contrário, comparece no conceito já apresentado de (SOARES, 2004), quando fala do divertir-se e da catarse. Quando nos voltamos, contudo, ao pensamento de Aristóteles (2005), vemos que a finalidade da tragédia era a imitação das ações de pessoas, da vida, da felicidade e desventura, de modo a inspirar pena e temor e operar a catarse própria dessas emoções. Assim, no contexto das elaborações deste pensador, quer lendo, quer assistindo a uma tragédia, o investimento passional no gozo da obra não constituía aniquilação do caráter estético do objeto artístico.

Útil é, então, a diferenciação que faz Roland Barthes (1993) entre prazer e fruição que, embora fenômenos distintos, não são, em seu pensamento, excludentes. $\mathrm{O}$ primeiro relaciona-se ao contentamento e o segundo ao desvanecimento, isso porque o prazer envolve a euforia, a saciedade e o conforto e a fruição, por sua vez, está relacionada à agitação, ao abalo e à perda. O prazer, assim, volta-se para a emoção, ao passo que, como declara o autor, a fruição é intransitiva e está "fora de qualquer finalidade imaginável" (BARTHES, 1993, p. 68). 
O prazer é agradável e a fruição pode até mesmo aborrecer, pois é forjada na tensão que se estabelece entre o texto e o leitor, do que resulta para este último perda e desconforto, pois o texto de fruição é aquele que, de acordo com Barthes (1993, p. 22), "faz vacilar as bases históricas, culturais, psicológicas, do leitor, a consistência de seus gestos, de seus valores e de suas lembranças, faz entrar em crise sua relação com a linguagem". Entendemos, então, que a fruição advém da crise a que a obra é capaz de fazer abater sobre o leitor, de colocá-lo em choque com seu universo até então conhecido, podendo daí o leitor derivar ou não o prazer.

Se, por um lado, o conceito de fruição de Barthes (1993) não exclui o prazer, embora não se confunda com ele; por outro, os conceitos de letramento literário - dos autores que estamos considerando nessa primeira parte de nosso artigo -, não abrem espaço para a leitura prazerosa na acepção barthesiana, e isso fica evidente nos trabalhos que discutiremos a partir de agora. Para Graça Paulino (2004), o leitor literariamente letrado é aquele que sabe escolher suas leituras, que aprecia construções e significações verbais de cunho artístico e que faz disso parte de seus afazeres e prazeres. Esse tipo de leitor, ainda de acordo com autora,

\footnotetext{
tem de saber usar estratégias de leituras adequadas aos textos literários, aceitando o pacto ficcional proposto, com reconhecimento de marcas linguísticas de subjetividade, intertextualidade, interdiscursividade, recuperando a criação de linguagem realizada, em aspectos fonológicos, sintáticos, semânticos e situando adequadamente o texto em seu momento histórico de produção (PAULINO, 2004, p. $56)$.
}

Vê-se, dessa citação, que não poucos conhecimentos se exige de um competente leitor de literatura. Percebe-se que para uma leitura adequada desse tipo de texto demanda-se não somente um bom nível de conhecimento linguístico e como esses elementos significam e a isso acresce-se a familiaridade com as exigências do gênero e das condições de produção do objeto artístico. Em outro lugar, a mesma autora define o sujeito literariamente letrado como aquele que cultiva e assume como parte de sua vida o texto literário, de modo a preservar seu caráter estético, e que aceita o pacto ficcional proposto e resgata objetivos culturais em sentido mais amplo e não objetivos funcionais ou imediatos para seu ato de ler (PAULINO, 2001).

Interessante notar das colocações dessa autora o fato de ela enfrentar a árdua tarefa de sublinhar os aspectos que interessam à formação do leitor literário e o que deve ser desprezado quando a perspectiva é a do letramento. Vejamos que Paulino valoriza os aspectos formais e aqueles ligados ao contexto de produção, ou seja, tantos os elementos interiores quanto os exteriores ao texto são relevantes no estudo do texto literário. Porém, os objetivos 
funcionais aí não entram, e aqui entendemos esse pensamento da estudiosa como uma referência, por exemplo, ao uso do texto para fins doutrinais, informativos, históricos, e outros.

No entanto, não são somente esses objetivos que ficam de fora de uma educação literária. Há também aqueles ligados à imediaticidade do ator de ler e, nesta direção, o entendemos como aquilo que Rildo Cosson (2007) chama de entretenimento, que a leitura literária pode proporcionar, ou, ainda, leitura recreativa, para tomar de empréstimo a ideia de Anne-Marie Chartier (1999). Cosson (2007) ainda nos diz que na escola a literatura é um lócus de conhecimento e que deve ser explorada de modo adequado para que funcione como tal. Porém, conhecimento para o autor restringe-se àqueles que mobilizam as faculdades racionais com o fim de conhecer e articular com proficiência o mundo feito de linguagem, o que equivale, na linguagem do autor, a analise literária.

Trata-se de uma perspectiva interessante, pois rompe com uma visão de estudo da literatura que se processa inteiramente no âmbito da história da literatura. Aqui se pode ver que o foco é o texto literário e sua exploração segundo instrumentos forjados pelas teorias da literatura e/ou literária. O texto, nesse caso, vem ocupar a cena no estudo da literatura. Nesta direção, então, para utilizar o pensamento de Marcelo Chiaretto (2007), a análise literária está na base do letramento literário, uma vez que disponibiliza procedimentos geradores e capacitadores que possibilitam a apropriação do mundo da escrita literária pelos leitores, posto que, para utilizar as palavras de Paulino (2011, p. 219), a "formação de um leitor de livros exige, principalmente, uma identificação cultural com o modo de ler esse objeto".

O leitor literário, pois, nessa ótica, muito menos importa sua identificação com a obra literária em si, mas com o modo como se lê determina obra. A grande questão que aí se coloca é que não há apenas um modo de ler uma obra literária, porque isso se decide pela filiação que o leitor faz a esta ou aquela orientação teórica ou mesmo conforme sua própria história de leitura o possibilite ler. Tal ato, então, para esses autores, parece acertado afirmar, estabelece relação com um certo modo de ler legitimado por determinadas instâncias legitimadoras, como, por exemplo, os especialistas da academia que se ocupam com as leituras literárias. A identificação, pois, não é com a obra literária em si, muito embora seja o texto literário no centro da cena de estudo, mas com os modos de ler legitimados por determinadas instituições com credenciais para dizer como deve ou não ser lida a literatura.

O modo de ler que podemos inferir desses postulados do letramento, que apresentamos até agora, a julgar pelos detalhes que nos oferece Paulino $(2001 ; 2004)$ e pelo 
que diz Cosson (2007), possibilita-nos relacioná-lo, ainda que não exclusivamente, com os saberes produzidos no campo da Poética. Muito embora essa palavra não tenha conservado o mesmo sentido ao longo dos tempos, Tzvetan Todorov (1973) nos assegura que, de um modo geral, a Poética, aqui nos restringindo à estrutural, "visa ao conhecimento das leis gerais que presidem ao nascimento de cada obra" (TODOROV, 1973, p. 15).

A Poética não diz respeito ao exame de uma obra particular, mas do delineamento de leis gerais que presidem o funcionamento da estrutura do literário, trata-se, logo, de "propor uma estrutura do funcionamento do discurso literário, uma teoria que apresente um quadro tal dos possíveis literários, que as obras literárias existentes apareçam como casos particulares realizados" (TODOROV, 1973, p. 15). Não é uma obra literária em particular que interessa, mas sim as leis que regem a estrutura segundo a qual o literário se realiza e, neste caso, "o texto particular não será senão um exemplo que permite descrever as propriedades da literatura" (TODOROV, 1973, p. 15).

Se, por um lado, esse é o interesse da Poética, por outro, aqueles que se ocupam da tarefa de interpretação dos textos literários podem nela encontrar instrumentos valiosos que lhes auxiliem visualizar o funcionamento da estrutura interna do objeto literário, posto que, nessa ótica,

a interpretação, ao mesmo tempo, precede e segue a Poética: as noções desta são forjadas de acordo com as necessidades da análise concreta, que por sua vez, não pode progredir a não ser que use os instrumentos elaborados pela doutrina (TODOROV, 1973, p. 17).

Em se tratando das consequências do uso dos conhecimentos da Poética nas salas de aula da escola secundária, podemos afirmar que, por um lado, os instrumentos elaborados pela poética podem estar a serviço de uma maior compreensão do texto literário, como colocou Cosson (2007). Por outro, o texto literário pode também comparecer apenas como mero ilustrativo para exemplificação de aplicação desses instrumentos, como é o caso do ensino francês, sobre o qual escreve Todorov (2009) em outro momento.

Contudo, não é verdade que esses autores postulam uma incursão no texto literário somente na perspectiva de seus elementos internos, uma vez que o sujeito literariamente letrado, segundo o ponto de vista que vimos falando, é aquele que também sabe relacionar a obra ao seu contexto de produção e que consegue resgatar objetivos culturais mais amplos. No entanto, mesmo levando em consideração os elementos internos e externos à obra, há uma vontade que subjaz a esse projeto, qual seja, o de assegurar uma abordagem racional, objetiva, do objeto artístico, logo trata-se de olhar o texto literário segundo uma perspectiva científica, 
o que corresponde, segundo Todorov (1973, p. 13), a "um dos sonhos do positivismo em Ciências Humanas".

É neste sentido, então, que estamos relacionando racionalização a esta vertente do letramento literário, posto tratar-se aí, como vimos, de um esforço em reduzir a abordagem do texto literário a uma única dimensão, a racional, o que implica, pois, em excluir do seu sistema lógico aquilo que não se conforma a essa dimensão. Há, neste ínterim, uma conexão entre essa orientação do letramento literário e a ordem paradigmática ainda vigente, a tradicional, cartesiana, e isso se dá pelo fato de que é a lógica dessa ordem que rege o modo como esses estudiosos formulam seu entendimento do que vem a ser letramento literário.

O modo de conceber o letramento literário orienta não somente o modo como se deve ler um texto literário, mas também o que pode ou não ser entendido como literário, e quando enunciamos a questão desta forma, estamos no campo dos 'valores' relacionados à escrita e leitura literárias. Egon Rangel (2007, p. 130) nos lembra que letramento é "um termo técnico que designa e articula entre si três ordens diferentes de fatores relacionados à linguagem escrita". Uma dessas ordens tem que ver com "os valores - inclusive éticos e estéticos - em nome dos quais a escrita participa da vida social, assim como os diferentes graus de intensidade dessa participação" (RANGEL, 2007, p. 130).

São esses valores associados à leitura literária que orientam a "concepção do que deva ser a 'boa leitura'” (RANGEL, 2007, p. 131, grifo do autor) e, consequentemente, a má leitura. Conforme vimos, são os instrumentos da Poética, de uma perspectiva interna, e recursos de outras áreas que permitem relacionar o texto à sua exterioridade, como, por exemplo, da história e sociologia da literatura que garantem uma boa leitura do ponto de vista do letramento literário na concepção dos autores até agora elencados. Ler bem, portanto, é ler na perspectiva de valor assumida por essa determinada vertente do letramento literário.

Conforme Todorov (1973, p. 123), "é uma verdade incontestável, hoje, que o juízo de valor sobre uma obra depende de sua estrutura" e que os valores extrínsecos à obra sejam legitimados pela tradição e, desse modo, acreditamos estar nos avizinhando do campo da Estética. Embora haja variação quanto ao que se entende por arte e, por conseguinte, sobre as teorizações a cerca da arte, entenderemos aqui por Estética a ciência "cujo objeto é o amplo reino do belo; de modo mais preciso, seu âmbito é o da arte, na verdade, a bela arte" (HEGEL, 2001, p. 27, grifo do autor).

Para Immanuel Kant (2010), o efeito estético está ligado à subjetividade do sujeito que entra em relação com determinado objeto, seja natural ou artístico. A representação 
estética, para o autor, é "aquilo que na representação de um objeto é meramente subjetivo, isto é, aquilo que constitui a sua relação com o sujeito e não com o objeto é a natureza estética dessa representação" (KANT, 2010, p. 32-33). O sentimento estético que o sujeito experimenta na relação que estabelece com seu objeto de contemplação está relacionado ao prazer ou desprazer derivado dessa relação; por isso podemos dizer que a estética kantiana valoriza a dimensão subjetiva do sujeito na apreciação de uma obra de arte.

Entretanto, não devemos pensar que as elaborações de Kant, a respeito da apreciação do belo, estejam voltadas para a valorização da subjetividade particular, ou seja, não há espaço aí para que o sujeito goze da obra de arte com todo investimento de suas paixões, de modo que cada sujeito possa emitir uma opinião pessoal, e todas elas serem igualmente válidas, mesmo que divergente. Muito embora o sentimento do belo esteja ligado à subjetividade, essa mesma subjetividade exige o acordo unânime das outras subjetividades, pois aquele que aprecia algo na perspectiva do belo "não tem que denominá-lo belo se apraz meramente a ele" (KANT, 2010, p. 57, grifo do autor).

Importante frisar que, mesmo em Kant, a subjetividade é vigiada, porque para que a leitura seja feita na perspectiva do belo, o atrativo e a comoção podem constituir impurezas que, na perspectiva do gosto, quer dizer, da faculdade de ajuizar o belo, devem ser evitados. Assim, a subjetividade de que fala Kant (2010) não deve ser confundida como uma licença para que cada sujeito ajuíze como bem o quiser a leitura de um texto literário na perspectiva do belo. Não há, pois, lugar para as operações catárticas, tal como em Aristóteles, ou para o prazer barthesiano, e é nesse sentido que entendemos o postulado de Kant (2010) de que a contemplação do belo é segundo uma complacência totalmente desinteressada, cujo resultado é, por sua vez, conforme palavras de Theodor Adorno (2008, p. 27), um “prazer sem prazer”.

Guardadas as particularidades, outros autores, como Georg W. F. Hegel $(1997 ; 2001)$ e Benedetto Croce (1997), que escreveram sobre Estética, também tiveram o cuidado de limitar a intensidade das emoções na apreciação da obra de arte bela. Muito embora sejam as paixões e os sentimentos em seus estados mais imediatos que animem a fantasia artística (HEGEL, 1997) ou a intuição (CROCE, 1997), quer no fazer artístico, quer na contemplação, esses materiais interiores necessitam de ser abrandados, ou expurgados, tanto no ato de criação como de criação.

Para Hegel (1997), a matéria-prima da poesia (aqui entendemos como literatura, conforme conhecemos hoje) é a fantasia e, logo, para o fazer literário, é de interesse a inteira dimensão da subjetividade humana, dado que o verdadeiro objeto da poesia é o reino infinito 
do espírito, que está relacionado ao subjetivo. Porém, todo esse material não deve se manifestar em estado bruto na arte literária. Conforme diz o autor, "a poesia não pode se contentar com as representações puramente interiores, mas que as há de receber para trabalhar, modelar e exprimir artisticamente" (HEGEL, 1997, p. 379). De modo similar, a leitura de uma obra bela não comporta comoção em sua contemplação, pois a ocupação com o belo, quer no fazer artístico, quer na apreciação "propicia o abrandamento do ânimo" (HEGEL, 2001, p. 29, grifo do autor).

Similarmente, Croce (1997) reconhece que a fantasia é o que anima o artista na sua criação, mas também, como os outros estudiosos da Estética já considerados, rejeita incisivamente a manifestação do passional em sua imediaticidade, quer no fazer artístico, quer no ato de contemplação. Para o autor, todo o conteúdo que anima o artista não deve aparecer na obra criativa em sua figuração imediata, mas, ao contrário, o criador deve engenhosamente trabalhar "a passagem do sentimento imediato para sua mediação e resolução na arte, do estado passional ao estado contemplativo" (CROCE, 1997, p. 128). Escrever e ler literatura, pois, na perspectiva acima abordada, ou seja, do gosto, não é uma tarefa que se presta facilmente, dado que, como bem reconhece o autor, "é sabido que o gosto, nos verdadeiros artistas e nos verdadeiros entendedores de arte, "se afina com os anos"” (CROCE, 1997, p. 132, grifo do autor).

Qual a relação de tudo isso com o letramento literário? A conexão que tentamos estabelecer foi uma que relaciona a vertente do letramento literário, que chamamos de cartesiano, e esses trabalhos da Poética e Estética que, em suas postulações para a apreciação da obra de arte, no nosso caso o texto literário, senão extirpam a dimensão passional do processo, ao menos a cerceiam em muito sua manifestação. A contemplação de uma obra de arte, segundo o que vimos até agora, é algo que se circunscreve a poucos, no mínimo especialistas, e não é, de longe, uma empreitada que se possa assumir sem arrojado conhecimento da tradição estética, poética e literária.

Uma das consequências da lógica desse discurso é que ele exclui os educandos da educação básica do contato efetivo com as obras literárias, porque pressupõe lograr sucesso em equipar os estudantes com instrumentos de análise para que eles, 'algum' dia, possam efetivamente entrar em conjunção com o objeto artístico. A grande questão é que os alunos da escola média ainda são leitores em formação, e aí se corre o risco de essa formação nem mesmo começar (na perspectiva da escolarização, conforme nos fala Soares (1999)), uma vez que esse é um processo que tem apenas início, e nunca fim. 
Percebemos, de entrada, que aqueles que frequentam a escola básica são os que ficam do lado de fora da apreciação estética na perspectiva valorativa de arte que essa vertente do letramento faz circular, pois a arte que agrada aos jovens, no dizer de Croce (1997), é a arte passional, qualificada de arroubo barato e que, longe de despertar o sentimento estético em direção ao gosto, provoca náuseas. Por seu turno, o artista digno de admiração é aquele mais difícil e incontestável e a crítica admirável se torna cada vez mais exigente, fervorosa e profunda.

Parece-nos, pois, bastante crível que há um certo esforço a perpassar todas essas elaborações que se inclina na direção de reduzir tanto o texto literário quanto o leitor da literatura a um único nível de realidade, o racional. Se, pois, arte se faz com ideia e técnica, por que, então, reduzi-la somente a técnica? Se, por um lado, o artista investe subjetividade e objetividade na construção do objeto artístico, por que o apreciador deveria, por seu turno, investir-se apenas racionalmente? O objetivo dessas perguntas é nos levar a ver que, por tudo o que estamos considerando, nem o texto literário nem seu leitor são levados plenamente em consideração. São, por assim dizer, chamados à cena da leitura sempre de modo parcial, privados da complexidade que os constituem.

Seriam desarrazoadas essas afirmações? Um modo de verificarmos uma resposta mais complexa a essa pergunta é por indagarmos pelo lugar da subjetividade em todos esses trabalhos. Há à subjetividade um lugar assegurado e legítimo aí tal qual é reservado aos estudos que se realizam mediante a razão? A resposta parece indicar que não e, assim, vamos afirmar, para adaptar aos nossos propósitos o pensamento de Michel Foucault (1987), que a leitura literária por esses trabalhos até agora apontados é, e sempre, vigiada; sobretudo contra as emoções, o que configura uma interdição ao bovarismo, para nos valermos do pensamento de Daniel Pennac (1993), com o fim de evitar que o leitor sobreponha "suas próprias expectativas de leitor empírico às expectativas que o autor queria que um leitor-modelo tivesse" (ECO, 1994, p. 16). Essas nossas conclusões encaminham-se no sentido da argumentação de Britto (2004, p. 48), quando diz: "mesmo no caso da leitura do texto literário, em que se valoriza a percepção subjetiva da realidade (...), prevalece, mesmo de forma mitigada, a centralidade do sujeito cartesiano".

\section{Algumas considerações}

Porém, na atual conjuntura da escola pública brasileira, levando em consideração a educação básica, a menor das preocupações que deveria prevalecer seria a formação de leitores-modelo, ideal, tendo em mente que o grande desafio que se coloca ainda se mostra 
aquém, qual seja, formar em alguma medida leitores. Quando a escola ignora o mundo subjetivo de seu leitor empírico, aquele que efetivamente a frequenta, pode ser mesmo que esteja fadada ao fracasso. Nunca é demais insistir que a literatura não esgota sua especificidade no nível do racional, mas que lhe é próprio jogar com muitas realidades que abarcam o real, o imaginário, o espiritual, o emocional e tantas outras dimensões e níveis de realidade, pois, como diz Wolgang Iser (2002, p. 958), "há no texto ficcional muita realidade que não só deve ser identificável como realidade social, mas que também pode ser da ordem do sentimental e emocional".

Percebemos, assim, que o letramento advogado por esse conjunto de trabalhos tem como alvo a formação de um leitor ideal, ou seja, aquele que está equipado com o somatório do conhecimento da tradição literária e que lê literatura e a analisa usando apenas a faculdade da razão. Essa forma de conhecimento do literário passa a largo da sabedoria complexa, uma vez que ignora que tanto o objeto artístico quanto o sujeito aprendiz são cosmos, um todo, multidimensionais e com vários níveis de realidade. Encerramos, assim, esta primeira parte do texto com a seguinte pergunta: pode o letramento literário empreendido de modo a ignorar a dimensão da subjetividade nos estudos envolvendo a literatura na escola ser adequado?

\section{Letramento literário na perspectiva da complexidade}

Essa parte de nossa investigação tem como objetivo discutir trabalhar que mostram que levar o letramento literário em consideração o investimento da dimensão passional por parte daqueles que leem literatura como característica constitutiva de leitores competentes desse tipo de texto não é atentar contra o caráter estético da arte da palavra, pois a noção de valor associada tanto à criação artística quanto à leitura literária pouco tem a ver com o objeto em si e mais com posições políticas e sociais a elas associada, logo, portanto, passível de ser alterada tão logo seja ajustada nossa escala de valores.

Por essa linha de raciocínio, não é a estrutura da obra literária, a forma segundo a qual se materializa o conteúdo do artístico que é determinante para que um artefato literário se torne uma obra clássica, muito embora esse aspecto contribua, pois aí importa o modo de organização do texto, o emprego de certa linguagem e a adesão a uma convenção como fatores contribuintes para que determinado texto seja literário. Porém, esses elementos por si só não bastam, pois "a 'literariedade' constitui-se também de elementos externos ao texto, como nome do autor, mercado editorial, grupo cultural, critérios críticos em vigor" (ABREU, 2006, p. 41, grifo do autor). 
Somente com muita dificuldade encontramos autores que inserem em seu conceito de letramento a dimensão subjetiva como constitutiva das habilidades e competências que se espera de um leitor literariamente letrado, fazendo-o, porém, sem postular uma subjetividade racionalizada. Em uma orientação parecida a de Márcia Abreu (2006), Maria Antonieta Pereira (2007) alarga o conceito de letramento para incluir também a dimensão subjetiva quando se propõe a pensá-lo como jogo.

Para Pereira (2007, p. 33), "pensar o letramento literário como um jogo é, portanto, trabalhar com a hipótese de um processo de leitura que considere uma ampla rede de subjetividades e sentidos". Nenhum dos autores que investigamos e que tratam do letramento literário de forma a conceituá-lo inclui de maneira nomeada a dimensão subjetiva como constitutiva do conceito, tal como o faz Pereira que, um pouco mais à frente em seu texto arrola algumas categorias que certamente ficam de fora na anterior orientação de letramento de que tratamos. Em suas palavras

\footnotetext{
o letramento literário deve assumir, cada vez mais, seu caráter de jogo - de ação livre, executada como expressão da imaginação e catarse, articulada nos níveis do possível, do impossível, do vivido e do contingente, sentida como algo que destrói os estereótipos do cotidiano e instaura o círculo mágico do prazer (PEREIRA, 2007, p. 44, grifo do autor).
}

Como podemos perceber, não há uma negação da dimensão subjetiva no processo de leitura de uma obra literária no conceito expresso por Pereira (2007) e, se é verdade que os demais autores com os quais já dialogamos não a negam explicitamente, pela rede de sentidos que pudemos estabelecer, não o fazem pela impossibilidade mesma que implica o conceito de estético, dado que a subjetividade segundo a lógica que os orienta deve ser purgada, expressa de forma serenizada, para não dizer racionalizada.

No entanto, no excerto do texto de Pereira (2007) podemos perceber que há uma valorização da subjetividade e com ela algumas categorias antes recusadas, como a imaginação e a catarse, o possível e o impossível, o vivido e o prazer. Vale ressaltar que este último termo, o prazer, não comparece aqui acompanhado do adjetivo desinteressado, tal como o é em Kant e, por conseguinte, nos demais que se filiam à sua orientação estética. Temos, pois, nesta definição de Pereira (2007) do que vem a ser letramento literário, um resgate do que foi deixado de fora e, mesmo rejeitado, nas definições anteriormente explicitadas.

É digno de notar que essa conceituação elaborada por Pereira (2007) reabilita à legítima leitura literária a dimensão catártica aristotélica bem como o prazer barthesiano. Desse modo, as percepções sensível e intelectual, fruição e prazer não entram na ordem da 
leitura literária em regime de exclusão e, à medida que cada uma dessas dimensões guarda suas particularidades, complementam-se, o que, certamente, torna a leitura literária mais rica e complexa. É nesse sentido que lemos as palavras de Pereira (2007, p. 33) quando ainda está elaborando seu conceito de letramento literário: "mas também requer dos sujeitos envolvidos em seu processo de ensino-aprendizagem níveis de reflexão cada vez mais dinâmicos e complexos".

Neste ponto de nossa argumentação, queremos relacionar os estudos de Abreu (2006) e Pereira (2007) à lógica do paradigma complexo, conforme já explicitamos, com base em Moraes (1997) e Morin (2008). Neste ínterim, podemos dizer que esse conceito de letramento literário funciona segundo a lógica da racionalidade, e não da racionalização, posto que não rejeita, não exclui de seu sistema lógico aquilo que lhe contraria, como, por exemplo, o impossível e a contingência.

Isso nos leva ao princípio dos diversos níveis de realidade que se estruturam segundo lógicas diferentes, o que constitui um dos pilares do pensamento transdisciplinar, tendo em vista que podemos visualizar aqui um conceito de letramento que não rejeita os instrumentos da Poética e que pode abrir caminhos para que a Estética tenha mais a dizer ao ensino da literatura, uma vez que legitima a subjetividade como uma dimensão fundante e não menos digna do que qualquer outra no fazer, fruir e derivar prazer da arte, sem, contudo, os cerceamentos da objetividade.

No ensino básico, objetividade e subjetividade não precisam rivalizar, quer dizer, de uma perspectiva transdisciplinar, cujo fundamento é o paradigma da complexidade, esses níveis, mesmo funcionando segundo lógicas diferentes, não guardam nenhuma hierarquia sobre o outro, o que significa que o estudo da literatura não precisa aspirar à objetividade com prejuízos à subjetividade. Todos os níveis têm a mesma importância e o que precisa ser empreendido é uma educação que alargue os níveis de percepção do educando, para que se possa conseguir passar de um nível ao outro em uma relação de complementaridade e não de exclusão.

Nesse sentido, o letramento literário poderá ser um instrumento eficaz na formação de leitores aptos a perceberem os jogos de linguagem em seus matizes sintáticos, fonéticos, fonológicos, semânticos... logo, da ordem do racional, como também a buscarem na literatura aquilo que dê forma às suas angústias, desejos, alegrias e etc. Buscar, enfim, nos textos literários aquilo que dê sentido à sua vida. Assim sendo, segundo a lógica do discurso do novo paradigma, as duas vertentes do letramento literário não estão em relação de exclusão, ou seja, 
ambas têm algo de muito importante a falar sobre a formação do leitor literário, colocando-se, pois, em relação de complementaridade. Porém, insistimos, essa última orientação já guarda uma relação de correspondência com a lógica do novo paradigma e se adéqua aos postulados da transdisciplinaridade e, por isso, estamos chamando-a de complexa.

O ensino da literatura necessita adaptar-se aos novos tempos e necessidades, quer sejam aquelas que operam na sociedade como um todo, quer aqueles que dizem diretamente da educação e, nesse sentido, uma das razões para a abertura do conceito de letramento a outras maneiras de se relacionar com o literário está ligada à emergência das propostas educacionais transdisciplinares que, no dizer de Pereira (2007), importa em uma das mais significativas consequências paradigmáticas na produção do saber.

A orientação anterior, a vertente que estamos chamando de cartesiana, embora, ao que parece, seja majoritária no campo de pesquisa do letramento literário, precisa alargar seus horizontes no que concerne às realidades que importam ser consideradas quando a questão é a formação de leitor literário, posto que a literatura, pela sua própria natureza, demanda do leitor investimento tanto de natureza objetiva quando subjetiva e, neste processo, ela exige que o leitor a ela se entregue por completo. É, pois, rumo à totalidade que o letramento deve avançar, tal como o está fazendo Abreu (2006) e Pereira (2007), sob pena de promover uma formação que já em seus primórdios nasce mutilada.

\section{Algumas considerações}

Das considerações que fizemos sobre a relação entre Poética, Estética e letramento literário - na vertente cartesiana, vimos que a preocupação é, antes, somente com o objeto, a arte, a literatura, com modos de ler, e isso de modo parcial, bem segmentado, nunca com aquele que contempla, que aprende a ler literatura. No enfoque da educação complexa, transdisciplinar, tudo isso é levado em consideração, e o aprendiz passa a ser visto não como um ser que deve aprender usando apenas a faculdade da razão e levado a racionalizar as emoções, ao contrário, agora ele "é um ser indiviso, para quem já não existe a fantasia da separatividade entre corpo e mente, cérebro e espírito, lado direito e esquerdo" (MORAES, 1997, p. 138), isso porque, como diz Morin (2007), o ser humano é a um só tempo físico, biológico, psíquico, cultural, social, histórico.

Importante trazer à atenção o fato de que não há mais hierarquias entre razão e emoção, pois a lógica do novo paradigma é a racionalidade e não a racionalização e, se assim é, os pares subjetividade/objetividade, interno/externo, racional/irracional e outros, deixam de ser vistos como excludentes e passam para um regime de complementaridade. Se a literatura 
corresponde "a uma necessidade universal, que precisa ser satisfeita e cuja satisfação constitui um direito" (CANDIDO, 1995, p. 242), a preocupação da escola aqui mais uma vez se desloca, passando, assim, do ensino à aprendizagem, uma vez que mais que ensinar, a escola precisa concentrar sua atenção na aprendizagem do aluno.

Nessa perspectiva de ensino da literatura, sob a ótica do letramento orientado pelo paradigma da complexidade, segundo princípios da transdisciplinaridade, os procedimentos da Poética têm seu lugar, bem como a Estética, somente os valores associados à leitura literária deixam de ser racionalizantes e, neste caso, então, a

literatura pode muito. Ela pode nos estender a mão quando estamos profundamente deprimidos, nos tornar ainda mais próximos dos outros seres humanos que nos cercam, nos fazer compreender melhor o mundo e nos ajudar a viver (TODOROV, 2009, p. 76).

Estamos, assim, nesse trabalho, em especial nessa seção, procurando ensaiar um modo de ver o ensino da literatura em uma perspectiva que não seja do fragmento, da exclusão, mas de forma a admitir que muitas são as potencialidades do texto literário e de seu destinatário, o leitor e, nessa relação, o processo pode ser de uma riqueza e natureza tais que, por mais esforços que façamos, talvez não o possamos apreender em sua totalidade, exatamente porque entendemos que a totalidade é assim, sabemos que ela existe, mas nunca conseguimos esgotá-la, senão visualizar apenas pequenos fios que a tecem. A literatura encerra mundos, o sujeito que a lê, também. São mundos, logo, em conexões e, aí, é forçoso que o conceito de letramento literário se alargue de modo a apontar para aquele momento da relação, como aponta Algirdas Greimas (2002), em que o objeto literário atinge seu potencial supremo e o leitor morre, ou alcança o êxtase em vida.

\section{Referências}

ABREU, M. Cultura letrada: literatura e leitura. São Paulo: UNESP, 2006.

ADORNO, T. Teoria estética. Trad. Arthur Morão. Lisboa, Portugal: Edições 70, 2008.

AKIKO SANTOS. Complexidade e transdisciplinaridade em educação: cinco conceitos para resgatar o elo perdido. In: AKIKO SANTOS; SOMMERMAN, A. Complexidade $e$ transdisciplinaridade: em busca da totalidade perdida. Porto Alegre: Sulina, 2009. p. 15-38.

ARISTÓTLES. A poética clássica. Trad. Jaime Bruna. 12.ed. São Paulo: Cutrix, 2005.

BARTHES, R. O prazer do texto. Trad. J. Buinsurg. 3.ed. São Paulo: Perspectiva, 1993.

BRASIL. Orientações Curriculares Nacionais: Linguagens, códigos e suas tecnologias. Ensino Médio. Brasília: MEC/ Semtec, 2006. 
BRITTO, L. P. L. Letramento e alfabetização: implicações para a educação infantil. In: FARIA, A. L. G.; MELlO, S. A. (Orgs.) O mundo da escrita no universo da pequena infância. Campinas: Autores Associados, 2005. p. 5-21.

Sociedade de cultura escrita, alfabetismo e participação. In: RIBEIRO, V. M. (Orgs) Letramento no Brasil: reflexões a partir do INAF 2001. 2 ed. São Paulo: Global, 2004. p. 89113.

CANDIDO, A. O direito à Literatura. In: Vários escritos. São Paulo: Duas Cidades, 1995, p. 235-263.

CAPRA, F. A teia da vida: uma nova compreensão científica dos sistemas vivos. Trad. Newton Roberval Eichemberg. São Paulo: Cutrix, 2006.

CHARTIER, A. M. Leitura e saber ou a literatura juvenil entre ciência e ficção. Tradução de BARROS, M. L. J. In: MARTINS, A. A.; BRANDÃO, M. B.; MACHADO, M. Z. V. (Orgs). Escolarização da leitura literária. Belo Horizonte: Autêntica, 1999. p. 59-69.

CHIARETTO, M. A leitura literária diante da visão moderna de progresso. In: PAIVA, A. et. al. (Orgs). Literatura e Letramento: espaços, suportes e interfaces, o jogo do livro. Belo Horizonte: Autêntica, 2007, p. 235-42.

COSSON, R. Letramento literário: teoria e prática. 1 reimp. São Paulo: Contexto, 2007.

CROCE, B. Breviário de estética/Aesthettica in nunce. Trad. Rodolfo Ilari Jr. São Paulo: Ática. 1997.

ECO, U. Seis passeios pelos bosques da ficção. Trad. Hildegard Feist. São Paulo: Companhia das letras, 1994.

FOUCAULT, M. Vigiar e Punir: O nascimento da Prisão. Trad. Raquel Ramalhete. 32.ed. Petrópolis: Vozes, 1987.

GREIMAS, A. J. Da imperfeição. Trad. Ana Cláudia de Oliveira. São Paulo: Hacker editores, 2002 .

HEGEL, G. W. F. Curso de estética: o sistema das artes. Trad. Álvaro Ribeiro. São Paulo: Martins Fontes. 1997.

Cursos de estética I. Trad. Marco Aurélio Werle. 2.ed. rev. São Paulo: USP, 2001.

ISER, W. Os atos de fingir ou o que é fictício no texto ficcional. Trad. Heidrun Krieger Olinto e Luiz Costa Lima. In: LIMA, L. C. Teoria da literatura em suas fontes. Vol. 2. Rio de Janeiro: Civilização brasileira, 2002. p. 955-84.

JAUSS, H. R. O texto poético na mudança de horizonte da leitura. Tradução de Marion S. Hirschmann e Rosane V. Lopes. In: LIMA, L. C. Teoria da literatura em suas fontes. Vol. 2. Rio de Janeiro: Civilização brasileira, 2002a. p. 873-919.

O prazer estético e as experiências fundamentais da poiesis, aisthesis e katharsis. In: JAUSS, H. R. et al. A literatura e o leitor: textos de estética da recepção. Coordenação e tradução de Luiz Costa Lima. 2.ed. Rio de Janeiro: Paz e Terra, 2002,. p. 85-104. 
KANT, I. Crítica da faculdade do juízo. Trad. V. Rohden e António Marques. 2.ed. Rio de Janeiro: Forense Universitária, 2010.

KLEIMAN, A. Modelos de letramento e as práticas de alfabetização na escola. In:

(Org.). Os significados do letramento: uma nova perspectiva sobre a prática social da escrita. 3 reimpr. Campinas: Mercado de Letras, 2001, p. 15-61.

KUHN, T. A estrutura das revoluções científicas. 3.ed. São Paulo: Perspectiva, 2009.

MORAES, M. C. O paradigma educacional emergente. 10.ed. São Paulo: Papirus, 1997.

MORIN, E. Os setes saberes necessários à educação do futuro. Trad. Catarina Eleonora F. da Silva e Jeanne Sawaya. 12.ed. São Paulo: Cortez; Brasília, DF: Unesco, 2007

2008.

Introdução ao pensamento complexo. 5.ed. Trad. D. Matos. Lisboa: Instituto Piaget,

NICOLESCU, B. O manifesto da transdisciplinaridade. Trad. Lucia Pereira de Sousa. São Paulo: TRIOM, 1999.

PAULINO, G. Letramento literário por vielas e alamedas. Revista da FACED, Salvador, n. 5, 2001. p. 117-26.

Formação de leitores: a questão dos cânones. Revista Portuguesa de Educação, Universidade do Minho, v. 17, n. 1, 2004, p. 47-62.

O acesso a impressos e à internet na formação de leitores. In: MARTINS, A. A. et. al. (Orgs). Livros e telas. Belo Horizonte: UFMG, 2011. p. 219 - 24.

PENAC, D. Como um romance. Trad. Leny Werneck. Rio de Janeiro: Rocco, 1993.

PEREIRA, M. A. Jogos de linguagem, redes de sentidos: leituras literárias. In: MARTINS, A. et. al. (orgs). Leitura literária: saberes em movimento. Belo Horizonte: Ceale; Autêntica, 2007. p. 31-46.

RANGEL, E. O. Letramento literário e livro didático de língua portuguesa: os amores difíceis. In: PAIVA, A. et. al. (Orgs). Literatura e Letramento: espaços, suportes e interfaces, o jogo do livro. 1 ed. 2 reimp. Belo Horizonte: Autêntica, 2007, p. 127-146.

SOARES, M. A escolarização da literatura infantil e juvenil. In: MARTINS, A. A.; BRANDÃO, M. B.; MACHADO, M. Z. V. (Orgs). Escolarização da leitura literária. Belo Horizonte: Autêntica, 1999, p. 17-48. 2001 .

Letramento: um tema em três gêneros. 2 ed. 3 reimpr. Belo Horizonte: Autêntica,

Letramento e escolarização. In: RIBEIRO, V. M. (Org) Letramento no Brasil: reflexões a partir do INAF 2001. 2.ed. São Paulo: Global, 2004. p. 89-113.

TFOUNI, L. V. Letramento e alfabetização. 7.ed. São Paulo: Cortez, 2005. 
TODOROV, T. Estruturalismo e poética. Trad. José Paulo Paes e Frederico Pessoa de Barros. 4.ed. São Paulo: Cutrix, 1973.

A literatura em perigo. Trad. Caio Meira. Rio de Janeiro: DIFEL, 2009.

ZUMTHOR, P. Performance, recepção, leitura. Trad. Jerusa Pires Ferreira. e Suely Fenerich. São Paulo: Cosac\&Naify, 2007.

[Recebido em junho de 2013 e aceito para publicação em outubro de 2013]

\section{Literary literacy: the literature reader construction at paradigm's transition times}

Abstract: This text is a chapter of our Master Thesis and discusses from the theoretical point of view that literature's images of readers are promoted by some works which are concerned by literary literacy's concept. These works have as aim to verify if they consider the real reader - whom is actually in elementary classrooms -, or the ideal reader - idealized by theoretical studies which are related to this type of reader -. The research is concerned into literature pedagogy field and it considers the emergent thought of complexity paradigm as well as transdisciplinarity. However, enlighten by the view of literary specificities, we bring to discussion writers from Aesthetics, Poetry and Literary Theory fields. The results show that most of the works promote the picture of ideal reader and for this reason, we classified them as Cartesian literary literacy; however, few of these works are related to complexity and transdisciplinarity studies, which led us to call them as complex literary literacy.

Keywords: Reader of literature. Literary literacy. Complexity.

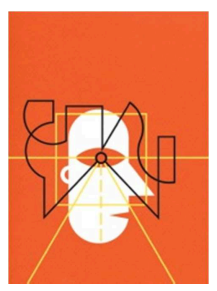

